\title{
Pengembangan Program Literasi Bahasa Berbasis Kelas di Lombok Barat: Potret, Program, dan Kebutuhan Era Digital
}

\author{
Syaiful Musaddat ${ }^{1}$, M. Syahrul Qodri ${ }^{2}$, Cedin Atmaja ${ }^{3}$, Murahim $^{4}$, Mari' $^{5}$ \\ ${ }^{12345}$ Jurusan PBS FKIP Universitas Mataram, Mataram; \\ Email: syaiful_musaddat@unram.ac.id ${ }^{1}$,syahrulqodri@unram.ac.id ${ }^{2}$, cedinatmaja@unram.ac.id ${ }^{3}$, \\ murahim@unram.ac.id ${ }^{4}$,dan marii@unram.ac.id ${ }^{5}$
}

\begin{abstract}
This study aims to describe the design profile of class-based language literacy programs in West Lombok Regency that suits the needs. This aspect of the study is focused on three things, namely: (1) a portrait of the implementation of class-based language literacy in West Lombok, (2) class-based language literacy programs that can be developed, and (3) the profile of an appropriate class-based language literacy program design model. needs. Data collection was carried out by observation, workshops, and FGDs. The data is sourced from Indonesian MGMP teachers in West Lombok district. Data analysis was carried out by following the principles in qualitative research, namely the data reduction stage, data presentation or organization, and data verification or interpretation. Based on the results and discussion, it can be concluded that the following matters. First, the implementation of class-based language literacy in West Lombok has not run optimally. Some of the conditions that prove this include: (a) no class literacy program or activity schedule is available; (b) fifteen minutes reading activity in each class is still rarely done; (c) class literacy activities have not been reflected in the learning tools developed by the teacher; and $(d)$ classroom literacy activities have not been reflected in the implementation of learning carried out by the teacher. Second, class-based language literacy programs that can be developed in schools include: making class posterization, making class literacy trees, making classroom reading corners, making class literacy work boards, empowering class wall magazine, and making a culture of reading non-learning books (story books) before, during, and after the learning process. Third, the class-based language literacy program design model that fits the needs is to give a touch of technology to all literacy program designs. For classroom posterization, reading corners, display boards, and so on are designed by utilizing technology. Including the provision of digital-based story books in the classroom. However, this design model certainly requires sufficient costs and expertise so that the participation of many parties is required. It is recommended for Indonesian language teachers to involve all school members to develop this chelation-based language literacy program.
\end{abstract}

\section{Keywords: Language Literacy, Class-Based, And Digital}

Abstrak. Kajian ini bertujuan mendeskripsikan profil disain program literasi bahasa berbasis kelas di Kabupaten Lombok Barat yang sesuai kebutuhan. Aspek kajian difokuskan pada tiga hal, yakni: (1) potret keterlaksanaan literasi bahasa berbasis kelas di Lombok Barat, (2) program-program literasi bahasa berbasis kelas yang dapat dikembangkan, dan (3) profil model disain program literasi bahasa berbasis kelas yang sesuai kebutuhan. Pengumpulan data dilakukan observasi, workshop, dan FGD. Datanya bersumber dari guru-guru MGMP bahasa Indonesia kabupaten Lombok Barat. Analisis data dilakukan dengan mengikuti prinsip-prinsip dalam penelitian kualitatif, yaitu tahap reduksi data, penyajian atau organisasi data, dan verifikasi atau interpretasi data. Berdasarkan hasil dan pembahasan, dapat disimpulkan hal-hal sebagai berikut. Pertama, keterlaksanaan literasi bahasa berbasis kelas di Lombok Barat belum berjalan maksimal. Beberapa kondisi yang membuktikan hal ini antara lain: (a) belum tersedia jadwal kegiatan atau program literasi kelas; (b) kegiatan lima belas menit membaca di kelas masing-masing masih sangat jarang dilakukan; (c) kegiatan litersi kelas belum tercermin pada prangkat pembelajaran yang dikembangkan guru; dan (d) kegiatan litersi kelas belum tercermin pada pelaksanaan pembelajaran 
yang dilaksanakan guru. Kedua, program-program literasi bahasa berbasis kelas yang dapat dikembangkan di sekolah antara lain: membuat posterisasi kelas, membuat pohon literasi kelas, membuat sudut baca kelas, membuat papan karya literasi kelas, memberdayakan mading kelas, dan membudayakan membaca buku nonpelajaran (buku cerita) sebelum, saat, dan setelah proses pembelajaran. Ketiga, model disain program literasi bahasa berbasis kelas yang sesuai kebutuhan adalah memberi sentuhan teknologi pada semua rancangan program literasi. Untuk posterisasi kelas, pojok baca, papan pajanan, dan lain sebagainya didisain dengan memanfaatkan teknologi. Termasuk penyediaan buku cerita berbasis digital di kelas. Namun demikian, model desain ini tentu membutuhkan biaya dan keahlian yang cukup memadai sehingga diperlukan partisifasi banyak pihak. Disarankan kepada guru bahasa Indonesia, agar melibatkan semua warga sekolah untuk mengembangkan program literasi bahasa berbasis kelasi ini.

Kata kunci: Literasi Bahasa, Berbasis Kelas, Dan Digital

\section{PENDAHULUAN}

Program literasi di Indonesia dikenal dengan nama Gerakan Literasi Sekolah (GLS). GLS mulai digagas sejak tahun 2015 melalui Permendikbud Nomor 23 Tahun 2015 tentang Penumbuhan Minat Baca melalui Kegiatan 15 Menit Membaca. GLS melibatkan semua pemangku kepentingan di bidang pendidikan, mulai dari tingkat pusat, provinsi, kabupaten/kota, hingga satuan pendidikan. Selain itu, GLS juga melibatkan unsur eksternal dan unsur publik, seperti orang tua peserta didik, alumni, masyarakat, dunia usaha dan industri (Depdikbud, 2018). Berdasarkan pedoman yang dikeluarkan kemdikbud, GLS dilaksanakan melalui tiga tahapan utama. Ketiga tahapan dimaksud adalah pembiasaan, pengembangan, dan pembelajaran. Tahapan ini dapat dilaksanakan di kelas (berbasis kelas), di sekolah (berbasis sekolah), dan masyarakat (berbasis masyarakat).

Seirin perkembangannya, literasi tidak lagi hanya terbatas pada kemampuan membaca, menulis, dan berhitung. Literasi kini terpapar pada berbagai bentuk dan dimensi yang lebih luas, yaitu: literasi bahasa, numerasi, sains, digital, finansial, serta budaya dan kewarganegaaran. Semua bentuk dan dimenasi literasi tersebut juga dapat dilaksanakan pada ketiga basis pelaksanaan literasi. Demikian pula literasi bahasa, juga dapat dilaksanakan berbasis kelas, sekolah, ataupun masyarakat.

Literasi bahasa berbasis kelas bermakna kegiatan literasi bahasa yang dilaksanakan terutama di kelas. Mengacu pada panduan pelaksanaan GLS, dapat dijelaskan bahwa terdapat sejumlah program yang menunjukkan kegiatan literasi bahasa berbasis kelas. Program literasi berbasis kelas dimaksud, yaitu: (1) menciptakan ruangan kelas yang nyaman dan penuh dengan nuansa yang mendorong siswa untuk membaca dan menulis. Media belajar dan kata-kata inspirasi dan motivasi dipajang di dinding kelas; (2) mengembangkan budaya baca-tulis melalui pembiasaan siswa untuk membaca dan menulis secara kontinyu (membaca buku sumber atau buku lainnya, lalu mengomentari dan atau merangkumnya sendiri). Hal ini sangat penting karena penggunaan buku cerita yang berhubungan dengan isi kurikulum dapat meningkatkan karakter siswa (kejujuran, kesabaran, dan kepatuhan untuk berdoa) bersamaan dengan kemampuan dalam mendengarkan dan membaca (Marhaeni, 2018: 517). Lebih lanjut dijelaskan bahwa cerita dapat digunakan sebagai alat pendidikan karakter; (3) mendorong siswa untuk terus berkarya melalui membaca dan menulis, yakni dengan membuat buletin kelas atau majalah dinding (mading) kelas, yang dilanjutkan dengan mengadakan lomba mading antarkelas agar semakin menggairahkan setiap kelas dalam berkreasi; (4) mengembangkan perpustakaan, area bacatulis, pustaka kelas atau pojok baca kelas (https://www.matra-pendidikan.com/2018/12/ penerapam-program-literasi-berbasiskelas.html, diakses 25 Agustus 2020). 
Penataan dan pengembangan programprogram kelas untuk mendukung terlaksanaannya program literasi bahasa berbasis kelas belum banyak dilakukan di sekolah-sekolah. Hasil observasi di beberapa sekolah Kabupaten Lombok Barat menunjukkan bahwa: (a) penataan ruang kelas termasuk posisi meja belajar belum tertata baik; (b) kelas terlalu padat karena ukurannya kecil tetapi isinya banyak; (c) ruangan kelas miskin dengan bahan cetak; dan (d) karya siswa tersimpan rapi dalam potofolio siswa di pojok/belakang kelas.

Hasil kajian awal yang dilakukan menunjukkan bahwa program literasi kelas belum berjalan secara efektif pada sekolahsekolah di Kota Mataram dan Lombok Barat. Beberapa indikator yang menunjukkan masih belum efektifnya pelaksanaan literasi bahasa di Lombok adalah sebagai berikut. (1) kegiatan lima belas menit membaca baru dilaksanakan secara bersama di halaman atau aula sekolah, yang di kelas masing-masing masih sangat jarang dilakukan (hanya dilakukan ketika materi pelajaran bahasa Indonesia); (2) kegiatan litersi kelas belum tercermin pada rancangan pembelajaran maupun pelaksanaan pembelajaran yang dilaksanakan guru; dan (3) hubungan sekolah dengan keluarga dan masyarakat belum terjalin dengan baik, termasuk dalam melaksanakan program literasi. Hampir semua sekolah tempat observasi, belum melibatkan orang tua siswa (keluarga) dan masyarakat dalam melaksanakan kegiatan literasi kelas.

Berdasarkan dasar pemikiran di atas, perlu dilakukan upaya konkret untuk mendukung keterlaksanaan program GLS. Salah satunya melalui kegiatan pelatihan mengembangkan program literasi bahasa berbasis kelas. Tulisan ini merupakan hasil kegiatan pengebdian kepada masyarakat melalui pelatihan pengembangan program literasi bahasa berbasis kelas bagi guru-guru bahasa Indonesia di Kabupaten Lombok Barat.

Melalui tulisan ini akan diuraikan tiga hal pokok, yakni: (1) potret keterlaksanaan literasi bahasa berbasis kelas di Lombok
Barat, (2) program-program literasi bahasa berbasis kelas yang dapat dikembangkan, dan (3) model desain program literasi bahasa berbasis kelas yang sesuai kebutuhan.

\section{METODE}

Secara metodologis, penelitian melalui program pengabdian ini dilakukan melalui tiga tahapan, yaitu (1) tahap prapenelitian atau penyusunan proposal, penyusunan instrumen penelitian, dan penyiapan alat dan bahan penelitian; (2) tahap penelitian yang mencakup pengumpulan dan analisis data; dan (3) tahap pascapenelitian yang mencakup penyusunan laporan penelitian. Pengumpulan data melalui metode observasi, pelatihan, dan FGD. Datanya bersumber dari kegiatan pelatihan yang dilakukan terhadap guru-guru bahasa Indonesia di Kabupaten Lombok Barat. Analisis data dilakukan dengan mengikuti prinsip-prinsip dalam penelitian kualitatif, yaitu tahap reduksi data, penyajian atau organisasi data, dan verifikasi atau interpretasi data. Sementara itu, metode penyajian data akan dilakukan dengan metode formal dan nonformal (Mahsun, 2018).

\section{HASIL DAN PEMBAHASAN}

Pada bagian ini akan dipaparkan hasil kajian dari pelatihan yang dilaksanakan. Penyajiannya akan disesuaikan dengan rumusan masalah yang dibahas, yakni: (1) potret keterlaksanaan literasi bahasa berbasis kelas di Lombok Barat, (2) program-program literasi bahasa berbasis kelas yang dapat dikembangkan, dan (3) model desain program literasi bahasa berbasis kelas yang sesuai kebutuhan.

\section{Keterlaksanaan Literasi Bahasa Berbasis Kelas di Lombok Barat}

Keterlaksanaan yang dimaksud pada bahasan ini adalah gambaran keterlaksanaan program literasi bahasa berbasis kelas pada sekolah-sekolah di Kabupaten Lombok Barat. Terutama di sekolah-sekolah asal peserta pelatihan. Adapun gambaran keterlaksanaan program literasi bahasa berbasis kelas pada sekolah-sekolah di Kabupaten Lombok Barat adalah bahwa pelaksanaan literasi bahasa 
berbasis kelas belum berjalan dengan efektif. Beberapa indikator yang menunjukkan masih belum efektifnya pelaksanaan literasi bahasa di Lombok adalah sebagai berikut.

a). Belum tersedia jadwal kegiatan atau program literasi kelas. Hampir semua sekolah tersebut, tidak bisa menunjukkan jadwal kegiatan atau program literasi kelas.

b). Kegiatan 15 menit membaca di kelas masing-masing masih sangat jarang dilakukan (hanya dilakukan ketika materi pelajaran bahasa Indonesia).

c). Kegiatan litersi kelas belum tercermin pada prangkat pembelajaran yang dikembangkan guru. Pada semua perangkat pembelajaran (RPP) guru dari sekolah-sekolah yang dikunjungi belum ada satupun yang pada RPP-nya terdapat program litersi.

d). Kegiatan litersi kelas belum tercermin pada kegiatan pembelajaran yang dilaksanakan guru. Pada semua tahapan pembelajaran yang dilaksanakan tidak ada yang mencerminkan kegiatan literasi.

Di samping itu, terungkap pula bahwa hubungan sekolah dengan keluarga dan masyarakat belum terjalin dengan baik. Termasuk dalam melaksanakan program literasi kelas. Hampir semua sekolah tersebut, belum melibatkan orang tua siswa (keluarga) dan masyarakat dalam melaksanakan kegiatan literasi kelas. Misalnya, sebagai model dalam pembelajaran/kegiatan literasi kelas. Padahal, menurut Elmacioğlu (2000), keberhasilan anak-anak di sekolah sangat terkait dengan lingkungan keluarga. Pollard dan Triggs juga menyatakan bahwa rumah, keturunan, evaluasi diri, dan usaha adalah di antara faktor-faktor yang mempengaruhi keberhasilan siswa (dalam Doğan dan Gönül Onur Sezer, 2010).

\section{Program Literasi Bahasa Berbasis Kelas}

Pada bagian ini disajikan temuan tentang berbagai program literasi yang dapat dikembangkan di Sekolah Kabupaten Lombok Barat. Program-program yang diusulkan disesuaikan dengan kondisi sekolah masing-masing peserta. Program-program yang diusulkan adalah: posterisasi kelas, membuat pohon literasi kelas, membuat sudut baca kelas, membuat papan karya literasi kelas, membuat mading kelas, dan membudayakan kegiatan membaca buku cerita sebelum, saat, dan setelah proses pembelajaran.

Temuan di atas sejalan dengan pandangan Faizah, dkk. (2016) yang menyatakan bahwa terdapat sejulmah program yang dapat digunakan sebagai kegiatan untuk menterjadikan literasi bahasa berbasis kelas yaitu sebagai berikut.

a). Pemberdayaan mading setiap kelas.

b). Merutinkan membaca buku nonpelajaran (buku cerita) sebelum proses pembelajaran.

c). Posterisasi kelas atau dinding motivasi kelas.

d). Membuat pohon literasi di setiap kelas.

e). Membuat sudut baca di setiap kelas.

f). Membuat papan karya literasi siswa di setiap kelas.

g). Pemilihan duta literasi kelas.

\section{Disain Program Literasi Bahasa Berbasis Kelas}

Desain program literasi bahasa berbasis kelas yang dimaksud dalam paparan ini adalah usulan model desain program literasi bahasa yang sesuai dengan kebutuhan dan tuntutan kemajuan teknologi. Dalam hal ini, yang disesuaikan dengan era digital. Adapun desain program literasi bahasa berbasis kelas sesuai tuntutan kebutuhan era digital yang direkomendasikan setelah diadakan pelatihan dan FGD adalah dengan memberi sentuhan teknologi pada semua program yang dikembangkan. Misalnya, untuk penyiapan kelas literasi berupa posterisasi, pojok baca, mading kelas, dan lain-lain seharusnya mendapat sentuhan teknologi. Hal ini sejalan dengan pandangan Beers, dkk. (2009), yang menyatakan bahwa salah satu strategi untuk menciptakan budaya literasi yang positif di kelas adalah mengkondisikan lingkungan fisik kelas menjadi ramah literasi. Dalam hal ini, lingkungan fisik kelas perlu terlihat ramah dan kondusif untuk pembelajaran. 
Kelas yang nyaman dan ramah untuk kegiatan literasi ditandai dengan penataan tertentu seperti: penataan pojok baca, pohon pajanan/papan pajanan, dinding motivasi, mading kelas, posisi duduk, dan lain sebagainya. Dalam hal ini, dengan memanfaatkan teknologi. Hasil penelitian Mabaso (2017) dan Hanover Research, juga menjelaskan bahwa desain sekolah untuk pendidikan abad 21 adalah menata ruang kelas dan lingkungan belajar lainnya dengan cara yang memenuhi beragam kebutuhan belajar. (www.hanoverresearch.com). Demikian pula dengan pandangan Kausar, dkk (2017), yang menemukan adanya pengaruh yang signifikan dari penataan ruang kelas terhadap prestasi akademik siswa. Penataan kelas yang efektif tidak hanya akan berdampak pada hasil belajar siswa, tetapi juga akan berakibat pada perubahan prilaku siswa (Hannah, 2013). Hal ini diperkuat oleh hasil temuan Padmini (dalam Rochmah, dkk., 2018) bahwa teknologi pendidikan terbukti dapat digunakan untuk meningkatkan hasil prestasi peserta didik dan mutu pendidikan yang ada serta menciptakan proses belajar mengajar yang kreatif, inovatif, menarik dan menantang.

Lebih dari itu, diperlukan pengembangan program lab digital di kelas. Yakni perangkat komputer yang dilengkapi berbagai data dan program untuk menunjang pelaksanaan literasi bahasa berbasis kelas. Siswa akan melalukan apa saja kegiatan literasi atau pembelajaran dalam sekali sentuh. Salah satu temuan Brown melalui penelitainnya yang berjudul Best Practices in $21^{\text {st }}$ Century Learning Environments: A Study of Two P21 Exemplar Schools tentang pembeda sekolah umum dengan sekolah model yang telah menerapkan program kemitraan untuk pendidikan abad 21 adalah pengalaman belajar sengaja diperluas dan terhubung ke dunia luar dengan memanfaatkan teknologi dan sumber daya yang ada (Brown, 2018: 13).

\section{KESIMPULAN}

Berdasarkan uraian pada bagian hasil dan pembahasan di atas dapat disimpulkan hal-hal sebagai berikut.

Pertama, keterlaksanaan literasi bahasa berbasis kelas di Lombok Barat belum berjalan maksimal. Beberapa kondisi yang membuktikan hal ini antara lain: (a) belum tersedia jadwal kegiatan atau program literasi kelas; (b) kegiatan lima belas menit membaca di kelas masing-masing masih sangat jarang dilakukan; (c) kegiatan litersi kelas belum tercermin pada prangkat pembelajaran yang dikembangkan guru; dan (d) kegiatan litersi kelas belum tercermin pada pelaksanaan pembelajaran yang dilaksanakan guru.

Kedua, program-program literasi bahasa berbasis kelas yang dapat dikembangkan di sekolah antara lain: posterisasi kelas, membuat pohon literasi kelas, membuat sudut baca kelas, membuat papan karya literasi kelas, memberdayakan mading kelas, dan membudayakan membaca buku nonpelajaran (buku cerita) sebelum, saat, dan setelah proses pembelajaran.

Ketiga, model disain program literasi bahasa berbasis kelas yang sesuai kebutuhan adalah memberi sentuhan teknologi pada semua rancangan program literasi. Untuk posterisasi kelas, pojok baca, papan pajanan, dan lain sebagainya didisain dengan memanfaatkan teknologi. Termasuk penyediaan buku cerita berbasis digital di kelas. Namun demikian, model desain ini tentu membutuhkan biaya dan keahlian yang cukup memadai sehingga diperlukan partisifasi banyak pihak.

\section{SARAN}

Beberapa hal yang dapat direkomendasikan sebagai saran dari hasil kegiatan ini adalah sebagai berikut. Pertama, guru bahasa Indonesia, agar melibatkan semua warga sekolah untuk mengembangkan program literasi bahasa berbasis kelasi ini. Kedua, kepela sekolah hendaknya memberi dukungan dalam bentuk dukungan kebijakan dan penyiapan sarana prasarana yang diperlukan. 


\section{UCAPAN TERIMAKASIH}

Ucapan terimakasih terutama disampaikan kepada semua guru-guru bahasa Indonesia, yang tergabung dalam MGMP bahasa Indonesia di Kabuapaten Lombok Barat. Ucapan yang sama juga disampaikan kepada semua tim, LPPM Unram, dn Prodi Pendidikan Bahasa dan Sastra Indonesia FKIP Unram yang telah mendukung terselesaikannya kegiatan ini.

\section{DAFTAR PUSTAKA}

Beers, C. S., Beers J. W., \& Smith J. O. (2009). A Principal's Guide to Literacy Intruction. New York: Guilford Press

Brown, Susan. (2018). Best Practices in $21^{\text {st }}$

Century Learning Environments: A

Study of Two P21 Exemplar Schools.

Brandman University, Irvine,

California School of

Education.https://digitalcommons.bra ndman.edu/cgi/viewcontent.cgi?articl $\mathrm{e}=1197 \&$ context=edd_dissertations

Depdikbud. (2018). Strategi Literasi dalam Pembelajaran di Sekolah Dasar (Modul Materi Penyegaran Instruktur Kurikulum 2013). Jakarta: Direktorat Pembinaan Sekolah Dasar, Dirjen Dikdasmen, Kementerian Pendidikan dan Kebudayaan

Doğan, Yadigar dan Gönül Onur Sezer. (2010). A Study on Learning Environments of Elementary School Students Taking Social Studies Course: Bursa Sample. "World Conference on Educational Sciences" (Istanbul, Turkey, February 4-8, 2010). co-organized by the Bahcesehir University. Turkey: Devid Publishing

Faizah, D.U., dkk. (2016). Panduan Gerakan Literasi Sekolah di Sekolah Dasar. Jakarta: Direktorat Pembinaan Sekolah Dasar, Dirjen Dikdasmen Hanover, Kemendikbud

Hannah, Riyan. (2013). The Effect of Classroom Environment on Student Learning. Western Michigan
University ScholarWorks at WMU. https://scholarworks.wmich.edu/ cgi/viewcontent.cgi? article $=3380 \& c$ ontext=honors_theses

https://www.matra-pendidikan.com/2018/12/ penerapam-program-literasiberbasis-kelas.html, diakses 25 Agustus 2020

Kausar, Ayesha at all. (2017). Effect of Classroom Environment on the Academic Achievement of Secondary School Students in the Subject of Pakistan Studies at Secondary Level in Rawalpindi District, Pakistan. Journal of Education and Practice ISSN 2222-1735 (Paper) ISSN 2222-288X (Online) Vol.8, No.24, 2017 hal 56-63 www.iiste.org

Mabaso, Bongani A. (2017). Twenty-first century skills development in rural school learners. Published by the University of Cape Town (UCT) in terms of the nonexclusive license granted to UCT by the author.

Mahsun. (2018). Metode Penelitian Bahasa. Depok: PT Raja Grafindo Persada

Marhaeni, Anak Agung Istri Ngurah, I Komang Wahyu Wiguna, I Made Gunamantha, and Nyoman Dantes. (2018) Content and Context: A Children's Book to Support Learning in the 2013 Curriculum. Advances in Social Science, Education and Humanities Research, volume 178. 1st International Conference of Innovation in Education (ICoIE 2018)

Rochmah, Eliya, Erna Labudasari, dan Nurani Amalia. (2018). The Usefull of Augmented Reality Over the National Insight in Learning Era Disruption-Based. 1 st National Seminar on Elementary Education (SNPD 2018) SHEs: Conference Series 1 (1) (2018) 232-239 